\title{
Slope stability modelling of a sandstone cliff south of Livorno (Tuscany, Italy)
}

\author{
D. Marchetti ${ }^{1}$, G. D’Amato Avanzi ${ }^{1}$, N. Sciarra ${ }^{2}$ \& M. Calista ${ }^{2}$ \\ ${ }^{1}$ Department of Earth Science, University of Pisa, Italy \\ ${ }^{2}$ Department of Geotechnology for the Territory and the Environment, \\ University of Chieti - Pescara, Italy
}

\begin{abstract}
The landscape of the coast south of the town of Livorno (Tuscany, Italy) is characterized by sandstone headlands and sandy pocket beaches. Lithological features and physical-chemical processes favour many slope failures (mainly rock slides and rock falls) involving the sandstone cliffs and extending all over the cliff height; these failures often threaten people and facilities. The most prominent positive relief landform is structurally controlled by three main, closely spaced orthogonal joint sets. The presence of leaning and collapsed rock blocks suggests that continuous sea erosion and mass wasting maintain the cliff slopes steepness and risk conditions. The sandstone mechanical properties and fracture pattern have been investigated in order to determine the response of the rock mass to subaerial and marine stress. Hardness and weathering of the rocks were assessed using a Schmidt hammer and the Point Load Test, and statistical analysis was undertaken to remove outlying values. The sandstone outcrops were characterized according to the Bieniawski's RMR and Romana's Slope Mass Rating. Such data have been reported in a GIS system in order to determine the landslide susceptibility of the cliff. A series of stability analyses, with a Distinct Element Method (DEM) model, were carried out to evaluate stress and displacement distribution near the free surface of a vertical slope face, as a function of steepness, dip direction and rock mass quality. The results showed that assessing block geometry could provide an effective tool in predicting the rock-mass stability, determining the mechanism by which blocks fail from a vertical slope, and the consequent repetitive slope failures through time.
\end{abstract}

Keywords: rock mass, rock fall, RMR, SMR, Distinct Element Method. 


\section{Introduction}

The coast south of Livorno, along the Ligurian Sea, shows predominant rocky shores, while beaches are small and rare. The Calafuria headland is greatly appreciated by tourists and bathers, because of its wonderful landscape, with windswept promontories and quiet coves, where the Libeccio (a violent south-westerly wind) causes spectacular and picturesque sea storms. Therefore, and particularly in the summertime many people frequent this area. Nevertheless, the coast around Calafuria hides some dangers, mainly due to sudden and rapid rock falls, which threaten the seashore and its access ways. This paper particularly focuses on the coast of the Calafuria headland, between the Rio Maroccone mouth to the north and the Leone cove to the south. It considers the most dangerous area, between the sea and the main road Aurelia and particularly aims at assessing the landslide hazard and modelling instability initiation and evolution.

\section{Geological setting}

Around Livorno, the geological setting may be schematized as a succession of tectonic units, referable to different paleogeographic domains (from west to east: Ligurian Domain, Sub-Ligurian Domain, and Tuscan Domain).

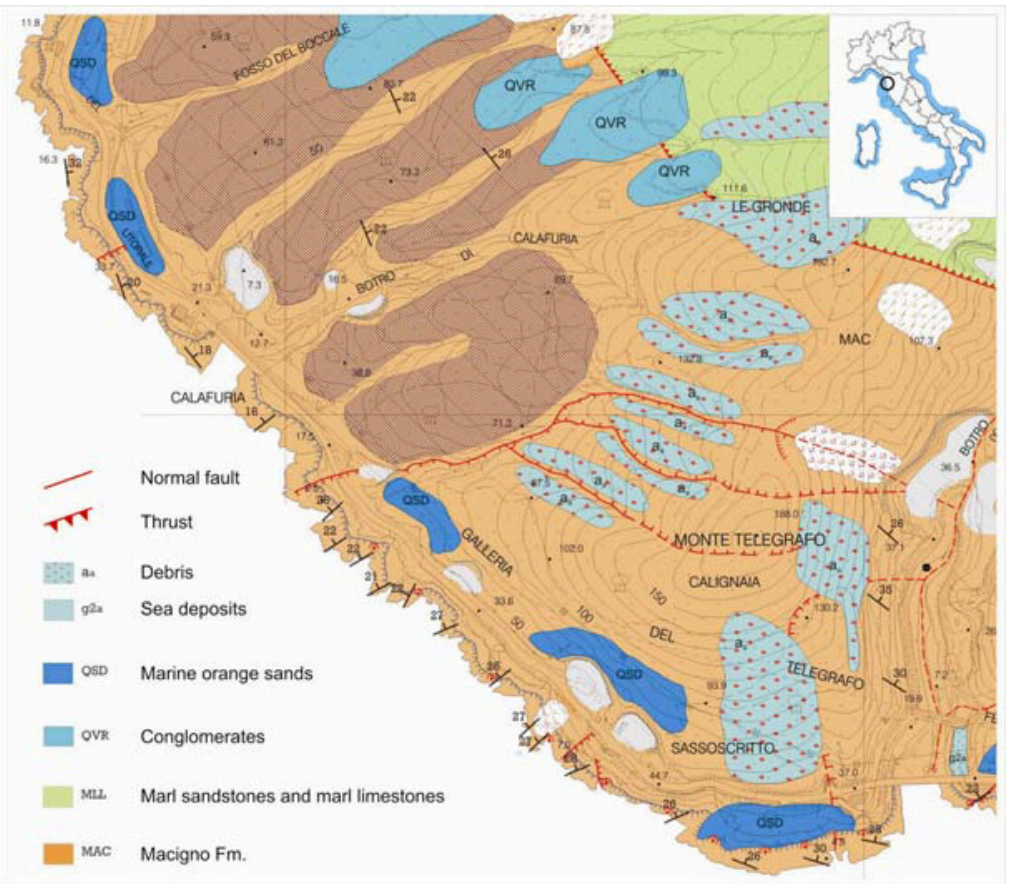

Figure 1: Geologic map of the study area. 
The Tuscan Nappe (Tuscan Domain) is the most widespread unit in Tuscany [5] and includes several formations ranging in age from Upper Triassic to Lower Miocene: among them the Macigno Fm. (Upper Oligocene-Lower Miocene) constitutes the studied cliff, while Ligurian and Sub-Ligurian units crop out all around (fig. 1). Pleistocene-Holocene, continental and sea deposits are also present, due to fluvial, slope and marine processes. The Macigno Fm. consists of mostly medium-to thick bedded siliciclastic turbidites made of grey-brown sandstone [17] and was named Arenaceous Flysch of Calafuria by Lazzarotto et al [15], as a lateral sediment easterly of the most typical Apenninic Macigno. It is well exposed at Calafuria and all along the marine cliff, where it shows a high sandstone/shale ratio and a predominantly thick-very thick, very coarse-grained (arenitic and ruditic) strata (fig. 2). This sandstone is mainly composed of quartz, feldspar and mica, with a high percentage of carbonate cement (about $9 \%$ of CaCO3) [10]. The depositional environment is mainly referable to channelled submarine fans [17]. Although the Bouma [3] sequence may be complete, the A unit, made of massive or graded beds prevails; thick and coarse facies and the amalgamation of beds are rather frequent.

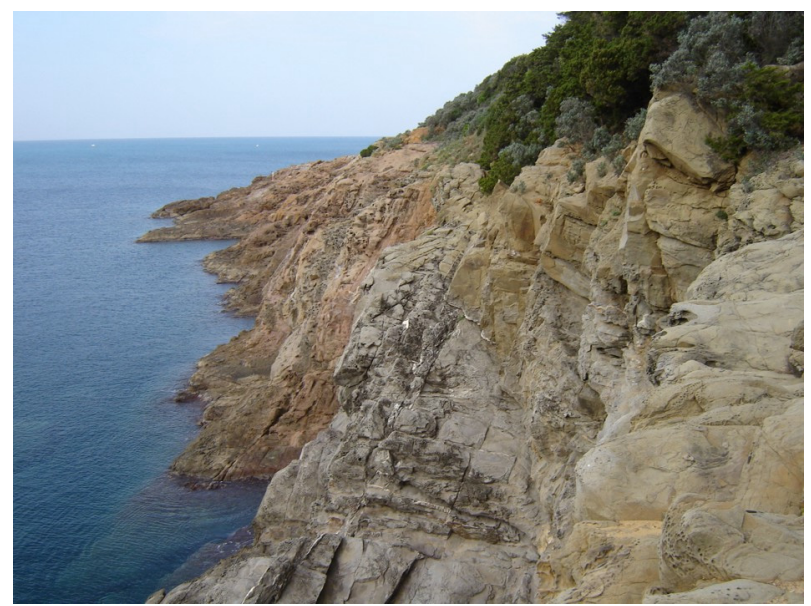

Figure 2: The Macigno Fm. is well exposed all along the marine cliff.

The structural arrangement of the study area results from different phases of corrugation and uplift of the Northern Apennines, which are a typical thrust-andfold chain. In this, the following events have been recognized $[6,8,16]$. Upper Cretaceous-Upper Miocene: a compressive deformation style was predominant and responsible for the emplacement of tectonic units from the above mentioned paleogeographic domains. Upper Miocene-Lower Pliocene: tensional tectonics began, causing NW-SE trending faults and brittle deformation; this deformation style could still be active. Folds, faults and joints testify this evolution in the study area. The Macigno Fm. show a mainly monocline structure, NW-SE trending and dipping $20-30^{\circ}$ into the slope. Along the coastline, bedding may be oblique to the slope direction. Faults show three main directions: NW-SE 
(Apenninic, normal faults), NS (normal faults) and NE-SW (Anti-Apenninic, transfer faults). Among them, the Mt. Telegrafo fault system displaces large fault blocks between Calafuria and Calignaia. Joints sets and bedding will be better analyzed afterwards, because of their fundamental role in controlling rock mass properties and slope instability. The present landscape results from several different processes, referable to the action of gravity, climate, running water, waves and tides, winds, and man. This area shows a typical indented, structurally controlled coastline and long rocky stiffs, which often hang over the shoreline.

Finally, it should be mentioned that recurrent earthquakes might hit the study area. In past centuries, four VII MCS (1646, 1742, 1771 and 1714) and a IX MCS (14/8/1846) occurred around Livorno. More recently, between the 2003-2007 period, six significant events have been recorded, with a magnitude up to 4.1 (Regione Toscana, web site). Therefore, the Livorno region has been included in the $3 \mathrm{~s}$ class of the seismic Italian classification $\left(\mathrm{a}_{\mathrm{g}}=0.25 \mathrm{~g}\right.$, where $\mathrm{a}_{\mathrm{g}}$ is the peak ground acceleration and $\mathrm{g}$ is the gravity acceleration). This contributes in worsening the stability conditions of the coast, and will be considered in the stability modelling of the cliff.

\section{Structural fabric of the Macigno Fm.}

The geotechnical study was carried out on the Macigno Fm. at the site. Field surveys and indirect tests for classifying the rock masses and estimating the uniaxial compression strength (UCS) were performed in the field with the Schmidt hammer and in the laboratory with the point load test.
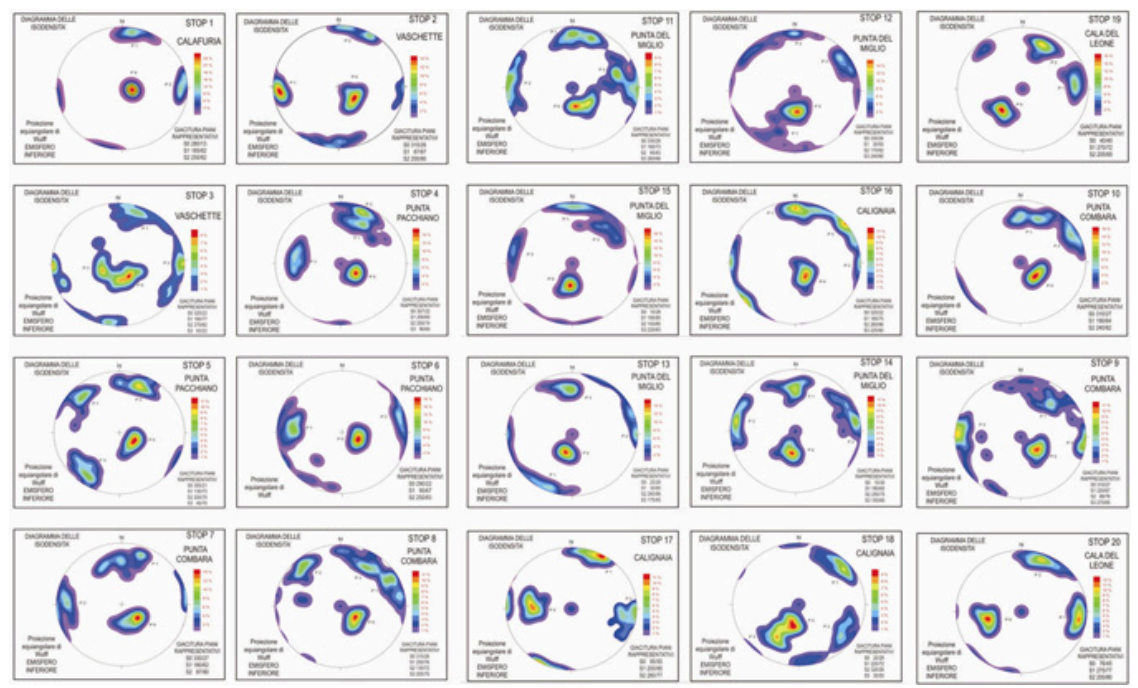

Figure 3: The structural fabric of the Macigno Fm. 
Fig. 3 depicts and synthesizes the structural fabric of the Macigno Fm., as resulted from the stereographic analysis (Wulff projection). The contour plots of the discontinuities are represented. Three median poles, corresponding to three median planes were identified. They may be assumed to be representative of three families of discontinuities (bedding and two joint sets), characterized by the following values of dip direction/dip. They are listed in order of decreasing frequency:
a. $320 / 24$ (bedding)
b. $\quad 190 / 70$
c. $250 / 80$.

\section{Geomechanical observations}

In the study area, a type-L hammer (impact energy of $0.735 \mathrm{Nm}$ ) was used. Various empirical equations have been proposed for estimating UCS from the Schmidt hammer rebound number (such as Deere and Miller [7], Katz et al. [14], Yasar and Erdogan [20], Aydin and Basu [1], Fener et al. [9]). In the study area the analyses were based on the well-known and commonly used Deere and Miller [7] relation, which easily allows comparison of the results. In order to estimate the UCS, it considers the hammer rebound and impact direction and the unit weight of the rock. The point load test, being basically a splitting test, needs to establish a relation between point load index and UCS and different studies have proposed different relations. Lacking any direct UCS determination, the procedure and relation proposed by Broch and Franklin [4] and ISRM [12] were used. They suggest that the UCS is about 24 times the point load index, referred to a standard size of $50 \mathrm{~mm}$. In the definition of the uniaxial compressive strength of the intact rock, an important index for the geomechanical classification, the values from the Point Load Test are considered more reliable than those gathered from the Schmidt Hammer, since the Point Load Test suffers from the fracturing of the rock mass less than the other instrument. Two representative domains of rock strength derive from the frequency distribution of Is(50) values obtained for the various samples. These sets are represented by modal values of Is(50) equal to $1.7 \mathrm{MPa}$ and $3.0 \mathrm{MPa}$, related respectively to samples with medium/coarse grain and fine grain; from these values the uniaxial compressive strength of the intact rock gives results equal to $41 \mathrm{MPa}$ and 72 Mpa respectively. According to the ISRM classification, the strength is moderately low in the coarse-grained samples and moderately high in the fine-grained samples.

\section{Geomechanical classifications of unstable rock masses}

\subsection{Rock Mass Rating}

In order to obtain a preliminary assessment of the rock mass instability, Bieniawski's Basic RMR (Rock Mass Rating) classification [2] was applied to the rocky wall. The $\mathrm{RMR}_{\mathrm{B}}$ can be very useful as a tool for the preliminary 
evaluation of geomechanical parameters of the rock mass, such as cohesion and friction angle.

In the study area there are three groups with different geomechanical qualities:

ZONE 1 - III class $\left(\mathrm{RMR}_{\mathrm{B}}=54\right)$ : Macigno Sandstone

This lithotype is well represented in the area. It shows a structural pattern with a regular bedding, with layers up to $30 \mathrm{~cm}$ thick. It has a medium UCS value (modal value of $72 \mathrm{MPa}$ ), with globally moderately widely spaced discontinuities; the conditions of the discontinuities vary from closed and dry to open and filled with incoherent material.

ZONE 2 - IV class $\left(\mathrm{RMR}_{\mathrm{B}}=36\right)$ : Macigno Sandstone

This lithotype differs from the other with a coarser grain; it shows a lower compressive strength and the discontinuity conditions are slightly poorer.

ZONE $3-\mathrm{V}$ class $\left(\mathrm{RMR}_{\mathrm{B}}=18\right)$ : Diaspri Fm. (Radiolarites)

These rocks show homogeneous and very poor geomechanical parameters, controlled by the frequent fragmentation of the rock. The radiolaritic type, closely bedded and sometimes interbedded to thin pelitic layers, can be considered resistant: the maximum UCS does not exceed 1.6 MPa at the Point Load test, a characteristic value of weak rocks. The discontinuities are very closely spaced [11] in the zones more affected by brittle deformation. To explain the stability conditions of the study area, it was considered necessary, once the geomechanical characteristics of the formations were defined, to analyze the relationship between slope and joints attitudes, for identifying unstable rock blocks and movements that may occur in static conditions. Afterwards it could be possible to consider induced loads, such as water pressure or seismic loads. The most critical areas for boulders and/or wedges detachment, as will be discussed in the following subsection, were identified by evaluating the stability of rock slopes, according to the SMR classification proposed by Romana [18, 19]. That classification, arisen from the RMR Index, considers the relationship between discontinuities and slope.

\subsection{Slope Mass Rating}

The SMR is obtained from the $\mathrm{RMR}_{\mathrm{B}}$ by adding an adjustment factor depending on the relative orientation of joints $(\alpha j ; \beta j)$ and slope $(\alpha s ; \beta s)$ and another adjustment factor depending on the method of excavation: $\mathrm{SMR}=\mathrm{RMR}_{\mathrm{B}}+(\mathrm{F} 1 \mathrm{x}$ F2 x F3) + F4. With the use of a GIS platform it has been possible to determine the areal changes of the Slope Mass Rating. The identification of areas with a higher probability of landslide movements has been achieved through the overlaying of different layers, each of which corresponds to the Romana classification factors (F1, F2, F3, F4). The following considerations arise from the maps:

- Planar sliding - Joint System A (320/24): the F1 factor is critical where the slope is $\mathrm{N} / \mathrm{NW}$ facing (because the planar sliding is more likely where joints and slope dip direction are similar). The F3 factor is critical in many areas because this system has a low dip value, so the situation "dipping 
downslope" is very frequent. However the planar sliding map shows that the rock mass stability is mostly controlled by the basic RMR.

- Planar sliding - Joint System B (190/70): this system is south facing, F1 will then be high where the slope has a similar dip direction; if the value of dip of these discontinuities is rather high $\left(70^{\circ}\right)$ then there will be critical conditions where the slope steeply dips towards the sea. Again, the planar sliding map shows that the rock mass stability is mostly controlled by the basic RMR.

- Planar sliding - Joint System C (250/80): joints belonging to the C family are W-SW facing, so the F1 values will be critical in the slopes with a similar dip direction; in this case F3 is less relevant than in the previous case because the dip is even higher $\left(80^{\circ}\right)$

- Toppling - Joint System A: F1 is critical where the slope is SE facing. The dip of these joints is very low so there is no toppling probability, in fact F3 everywhere is equal to zero.

- Toppling - Joint System B: the F1 value is low throughout the study area because there are no North facing slopes. F3 reaches critical values where there are slopes $\geq 50^{\circ}$ steep.

- Toppling - Joint System C: F1 is critical where slopes are E-NE facing (only in a small area north of the Calignaia bridge). For F3 the same observations made for the family B are applied. These two factors affect the slope stability, but it is generally governed by the geomechanical quality of the Macigno Fm.

It's clear that the stability of the rock mass that constitute the Romito's sea cliff are linked to the rock mass quality (and therefore the structural domain in which it falls) more than to the relationship between joints and slope attitudes.

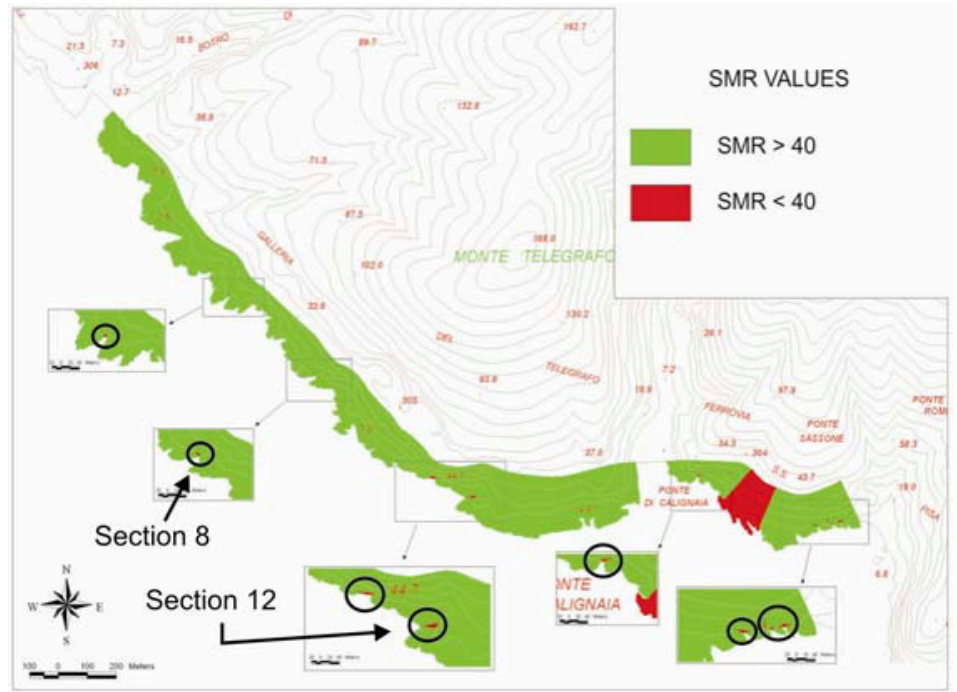

Figure 4: In the map the areas with SMR index $<40$ are the dark grey ones. The two sections for the analyses are shown. 
These observations were summarized in a map of areas with a SMR index $<40$, shown in fig. 4 . The classification provides a high probability of all types of movements, planar sliding, wedge sliding or toppling, where the index is less than this value.

\section{Numerical modelling}

After geomechanical surveys we performed some numerical analyses on two particularly interesting sections (fig. 5), located on the map shown in fig. 4, using a bi-dimensional distinct-element method (Udec_4.0 code, [21]) that simulates the response of discontinuities, such as fractured rock mass, subjected to static and dynamic stress. The mass was discretized in irregular polygons, due to the natural discontinuities, and the numerical code permits analysis of their displacements and deformation coupling the motion equations with those of the constitutive laws. The mass was represented by a set of distinct blocks; discontinuities are considered to be the boundary of each block; great displacements along the discontinuities and rotations were permitted. UDEC utilizes different constitutive models both for material and the interfaces between the fractures.

From a geological point of view the two selected sections are constituted by only one lithotype, sandstone of the Macigno Formation. The fracture families, for each section, represent the natural stratification (S0 in fig. 5) and two important and main discontinuities (S1 and S2 in fig. 5).

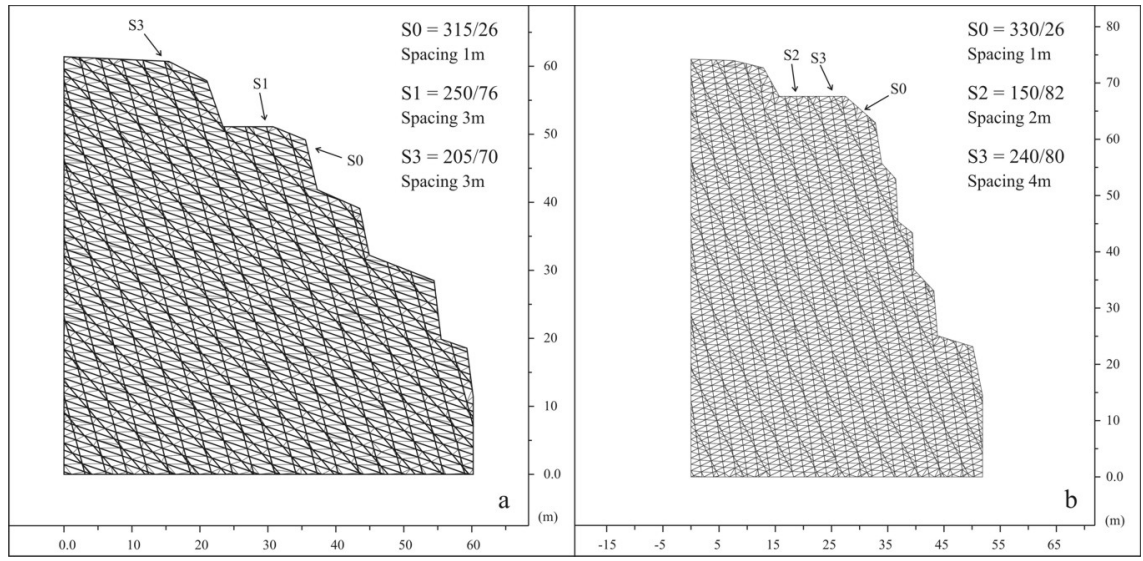

Figure 5: Discretization mesh and discontinuities families for the selected sections (a) n.8 and (b) n.12.

The static and dynamic analyses were carried out attributing to the rock the Hoek and Brown criterion that is expressed by $\sigma_{1}=\sigma_{3}+\sigma_{c i} \cdot\left(m_{b} \frac{\sigma_{3}}{\sigma_{c i}}+s\right)^{a}$; where $\sigma_{1}$ is the main principal stress, $\sigma_{3}$ is the minus principal stress, $\mathrm{m}_{\mathrm{b}}, \mathrm{s}$ and a 
are constant depending on the rock quality (density, fracturing degree, plasticity, rupture shear resistance, etc.) and $\sigma_{c}$ is the characteristic strength of the intact rock. The utilized mechanical parameters were: unit weight $(\gamma)=26 \mathrm{kN} / \mathrm{m}^{3}$; bulk modulus $(\mathrm{K})=10 \mathrm{GPa}$; shear modulus $(\mathrm{G})=5.5 \mathrm{GPa} ; \mathrm{m}_{\mathrm{b}}=2.18 ; \mathrm{s}=0.0039 ; \mathrm{a}=$ $0.506 ; \sigma_{\mathrm{c}}=41 \mathrm{MPa}$.

We utilized the Mohr-Coulomb criterion relatively to the interfaces of the discontinuities because their properties are functions only of a frictional and cohesive behaviour. In this case the needed parameters are: normal stiffness $(\mathrm{Jkn})=1 \mathrm{E} 10 \mathrm{~Pa} / \mathrm{m}$; shear stiffness $(\mathrm{Jks})=1 \mathrm{E} 9 \mathrm{~Pa} / \mathrm{m}$; friction degree $(\varphi)=27^{\circ}$; cohesion $=220 \mathrm{kPa}$ in section $\mathrm{n} .8$ and 190 in section $\mathrm{n} .12$ for $\mathrm{S} 0$ discontinuities; cohesion $=40 \mathrm{kPa}$ for all the others interfaces. All the parameters had been selected from laboratory tests and the scientific bibliography.

\subsection{Section n. 12 results}

The analysis in static conditions (only gravity) had showed instability outside of the slope (fig. 6a); at the top we recognize sliding movements along the fracture planes while at the bottom the blocks suffer toppling phenomena. The monitored displacement vectors (see fig. 6a for the location of monitored points) show stability only for the point n.1, the others are unstable, in fact their trend versus time (fig. 6b) increases. On this section we have not been able to study dynamic conditions because the instability already occurred during the static analysis.
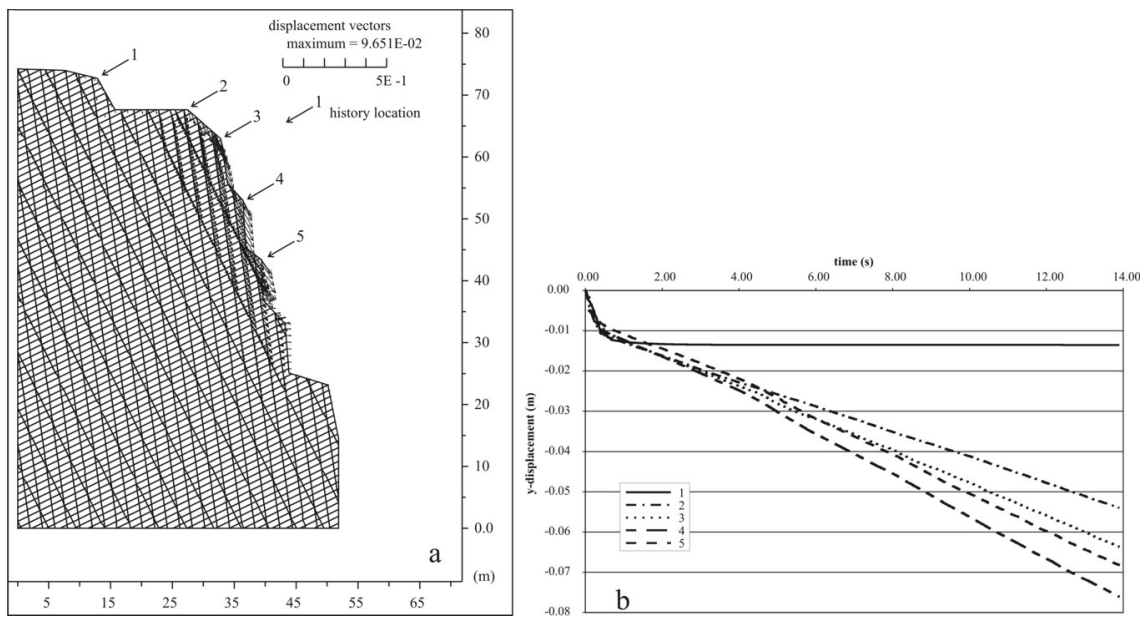

Figure 6: Displacements vectors in the section n. 12 (a) and vertical movements in monitored nodes (b).

\subsection{Section $n .8$ results}

In static conditions the analysis shows a good stability. In fig. 7 it is possible to note the very low values of the induced displacements (a few millimetres). The bottom part of the section is typically more involved in the movement of a 
sliding. On this section we have been able to execute a dynamic analysis because the model had reached the convergence in the equilibrium of the lithostatic conditions. We have utilized seven accelerograms (fig. 8, unpublished data) with a return period of 475 years, a magnitude between 5.5 and 6.0 and an epicentre distance of less than $20 \mathrm{~km}$ to investigate all the possible seismic situations.

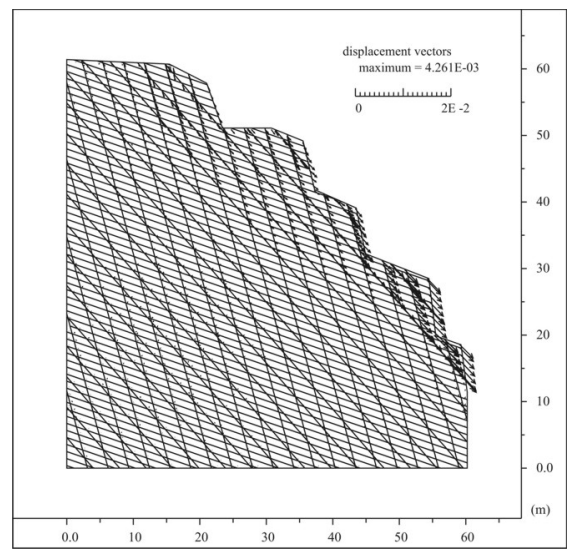

Figure 7: Displacements vectors in section n.8.
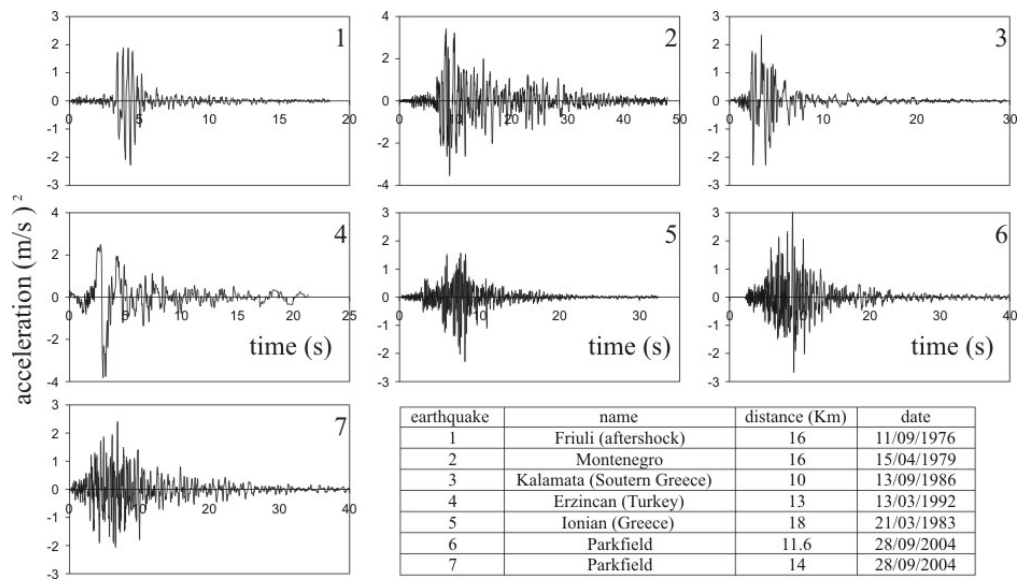

Figure 8: $\quad$ Seismic accelerograms used in the dynamic analysis.

In this way we could have distinguished two different movements regarding the 2, 3 and 4 seismic inputs and the 1, 5, 6 and 7 inputs (see fig. 8 for the identification of the seismic inputs). In any case the system was unstable. To understand the results of the two responses we analyzed the 4 and 5 inputs. Observing fig. 9 (relative to input n. 4) we can note a roto-translational movement that involves the whole slope (fig. 9a) and in the exterior right lower 


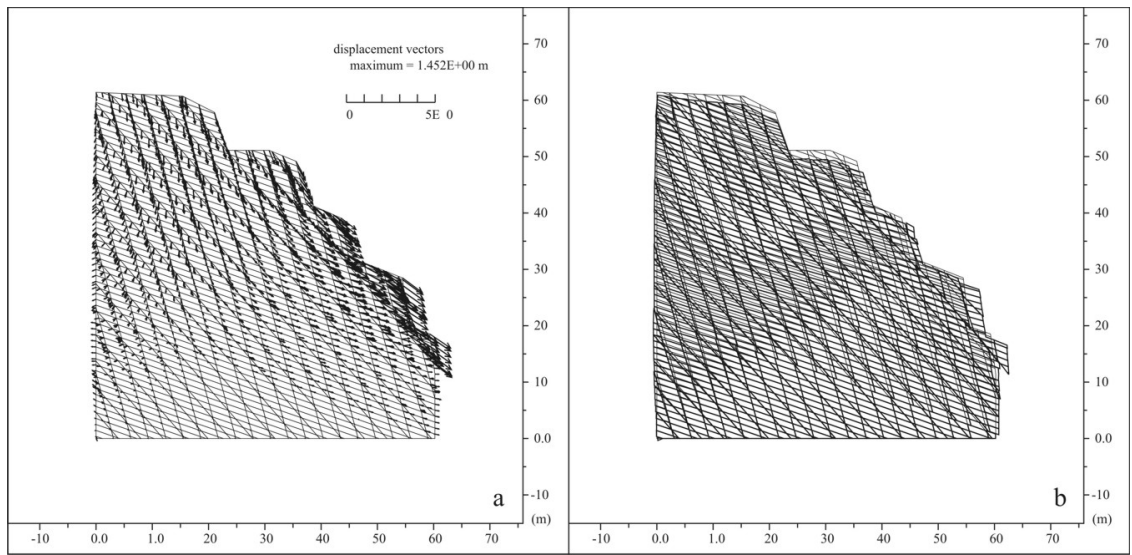

Figure 9: Displacements vectors (a) and block deformation (b) related to seismic input n. 4 .

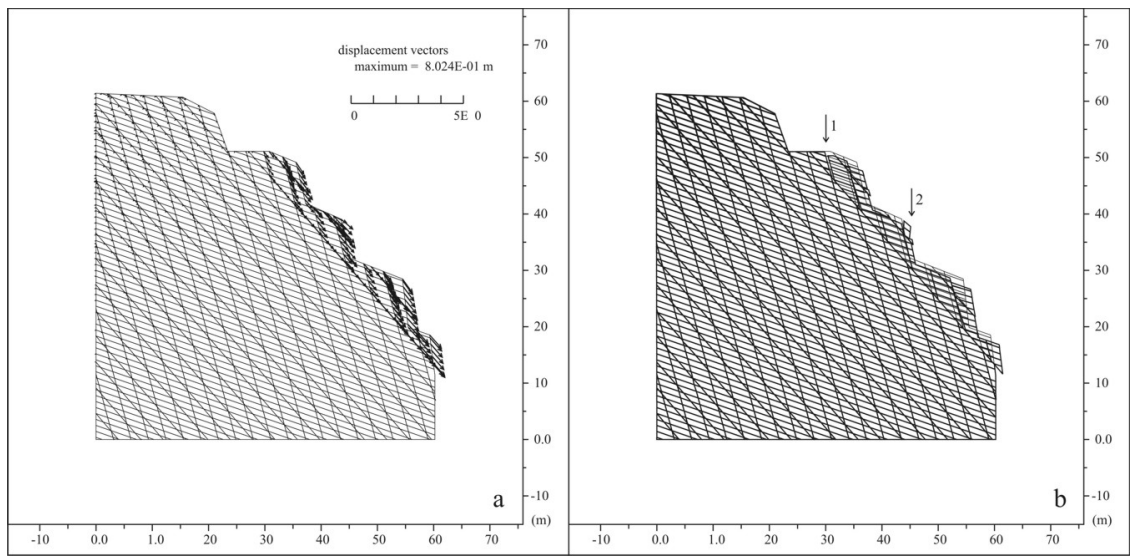

Figure 10: Displacements vectors (a) and block deformation (b) related to seismic input n. 5 .

zone of the section some blocks tend to topple rolling (fig. 9b). With input n.5 the results are different; only the external part of the section is subjected to a movement, typical of a plane failure, along the fracture related to the S3 family.

The sliding is well defined and clear (fig. 10a) and we can see in fig. 10b the nodes in which detachment starts (node n.1) and some blocks also roll (node n.2).

\section{Conclusions}

This study has examined a sandstone cliff south of the town of Livorno, between the Rio Maroccone mouth to the north and the Leone cove to the south, in its most dangerous area, between the sea and the main road Aurelia. The aim of this 
study was to divide the area into homogeneous hazard classes and assess the possible kinematic evolution. The study refers to an evaluation of parameters that may trigger rock falls on the cliff, which could constitute dangers for tourists. The identification of critical areas has been achieved through the elaboration of landslide susceptibility maps. The geotechnical study was carried out on the Macigno Fm. at the site. Field surveys and indirect tests for classifying the rock masses and estimating the uniaxial compression strength (UCS) were performed. Some numerical analyses were executed to study the static and dynamic behaviour of the slope. The results confirm the vulnerability of the area, demonstrating the dynamic instability on the analyzed sections and a precarious equilibrium is also in static conditions. These analyses, compared with the site surveys, show poor data and in some cases alarming results: some portions of cliff are under limit equilibrium conditions or close to it, especially in some areas appreciated by tourists and bathers. Through the numerical modelling the critical situation of these slopes becomes even more evident, confirmed by some rock falls of small blocks occurred during the geomechanical survey period. To make the situation worse, the whole area is constantly subject to exogenous agents such as strong winds and the wave action, which determine a rapid deterioration of the mechanical characteristics of strength in the Macigno Sandstone.

\section{Acknowledgement}

This study was supported by MIUR-Italian Ministry of Education funds (PRIN 2005-Geological and geotechnical characterization of natural slopes and slope stability analysis in seismic areas of the Northern Apennines, Italy).

\section{References}

[1] Aydin, A. \& Basu, A., The Schmidt hammer in rock material characterization. Eng Geol, 81, pp. 1-14, 2005.

[2] Bieniawski, ZT., Engineering Rock Mass Classifications. Wiley, New York, 1989.

[3] Bouma, A.H., Sedimentology of some flysch deposits: a graphic approach to facies interpretation, Elsevier: 168 pp., 1962.

[4] Broch, E. \& Franklin, JA., The Point Load Strength Test. Int J Rock Mech Min Sci, 9, pp. 669-697, 1972.

[5] Carmignani, L. \& Lazzarotto A., Geological Map of Tuscany (Italy), Regione Toscana, Spec. Edition for the 32nd IGC. Tip. LAC, Firenze, 2004.

[6] Conti, P. \& Lazzarotto, A., Geology of Tuscany: evolution of the state-ofknowledge presented by geological maps and the new geological map of Tuscany, 1:250,000 scale. In: Morini D, Bruni P (eds) The Regione Toscana project of geological mapping. Spec. vol. for the 32nd IGC, Florence: 25-50, 2004. 
[7] Deere, DU. \& Miller, RP., Engineering classification and index properties for intact rocks. Air Force Weapons Lab. Tech. Report, Kirtland Base, New Mexico, AFWL-TR, pp. 65-116, 1966.

[8] Elter, P., Giglia, G., Tongiorgi, M. \& Trevisan, L., Tensional and compressional areas in the recent (Tortonian to present) evolution of the Northern Apennines. Boll. Geofis. Teor. Appl., 17, pp. 3-18, 1975.

[9] Fener, M., Kahraman, S., Bilgil, A. \& Gunaydin, O., A comparative evaluation of indirect methods to estimate the compressive strength of rocks. Rock Mech Rock Eng, 38(4), pp. 329-343, 2005.

[10] Ferrini, G., Pandeli, E. \& Coli, M., Facies e sequenze verticali nel Macigno di Calafuria (Livorno). Boll. Soc. Geol. Ital, 104, pp. 445-458, 1995.

[11] ISRM, Suggested methods for the quantitative description of discontinuities in rock masses. Int J Rock Mech Min Sci Geomech Abstr, 15, pp. 319-368, 1978.

[12] ISRM, Rock Characterization, Testing and Monitoring: Suggested methods. Pergamon Press, 1981.

[13] ISRM, Suggested methods for determining point-load strength. Int J Rock Mech Min Sci Geomech Abstr, 22, pp. 53-60, 1985.

[14] Katz, O., Reches, Z., Roegiers, JC., Evaluation of mechanical rock properties using a Schmidt hammer. Int J Rock Mech Min Sci, 37, pp. 723-728, 2000.

[15] Lazzaretto, A., Mozzanti, R. \& Nencini, C., Geologia e morfologia dei Comuni di Livorno e Collesalvetti (with 1:25000 geological map). Quad. Mus. Stor. Nat. di Livorno, 11, Suppl. 2, pp. 1-85, 1990.

[16] Mazzanti, R. - Revisione e aggiornamento sui movimenti tettonici deducibili dalle dislocazioni nei sedimenti pleistocenici ed olocenici della Toscana costiera. Studi Geol. Camerti, Spec. Vol. 1995/1, pp. 509-521, 1995.

[17] Pandeli, E., Ferrini, G. \& Lazzari, D., Lithofacies and petrography of the Macigno formation from the Abetone to the Monti del Chianti areas (Northern Apennines). Mem. Soc. Geol. Ital., 48, pp. 321-329, 1994.

[18] Romana, M., New adjustment ratings for application of Bieniawski classification to slopes. In: Int. Symp. on the Role of Rock Mechanics, Zacatecas, pp. 49-53, 1985.

[19] Romana, M., A geomechanical classification for slopes: slope mass rating. In: JA Hudson (ed) Comprehensive rock engineering, 3, Pergamon, pp. 575-600, 1993.

[20] Yasar, E., Erdogan, Y., Estimation of rock physicomechanical properties using hardness methods. Eng Geol, 71, pp. 281-288, 2004.

[21] UDEC version 4.0, Itasca consulting group, inc., - Minneapolis, USA, 200 